\title{
Intraductal tubulopapillary neoplasm (ITPN) of pancreas with polycystic kidney and liver disease
}

\author{
Kwang Yeol Paik \\ Department of Surgery, Yeouido St. Mary's Hospital, College of Medicine, The Catholic University of Korea, Seoul, Republic of Korea \\ Correspondence to: Kwang Yeol Paik, MD, PhD. Department of Surgery, Yeouido St. Mary's Hospital, College of Medicine, The Catholic University \\ of Korea, 10, 63-ro, Yeongdeungpo-Gu, Seoul 07345, Republic of Korea. Email: kpaik@outlook.com. \\ Provenance and Peer Review: This article was not commissioned by the editorial office. The article was not sent for external peer review.
}

Submitted Nov 24, 2019. Accepted for publication Jan 08, 2020.

doi: $10.21037 /$ hbsn.2020.02.05

View this article at: http://dx.doi.org/10.21037/hbsn.2020.02.05

A 64-year-old man presented to pain in the left upper quadrant and weight loss. Findings on magnetic resonance imaging (MRI) of the abdomen included the filling of mass in whole pancreatic ducts with marked dilatation (Figure 1A,B, within yellow dots). Total pancreatectomy was performed and whole pancreas replaced by intraductal mass like lesion (Figure 1C). Mural nodules filled with the whole pancreas. Pathologic result revealed intraductal tubulopapillary neoplasm (ITPN) with invasive carcinoma.
At a follow-up 4 years after surgery, he died with polycystic kidney infection without evidence of ITPN recurrence.

ITPN is a rare pancreatic tumor belonging to a newly recognized entity that is updated in the $2010 \mathrm{WHO}$ classification. It is definite difference between intraductal papillary mucinous neoplasm (IPMN). There were few reports of IPMN with polycystic kidney and liver disease but it is first report ITPN with polycystic kidney and liver disease on the literature.
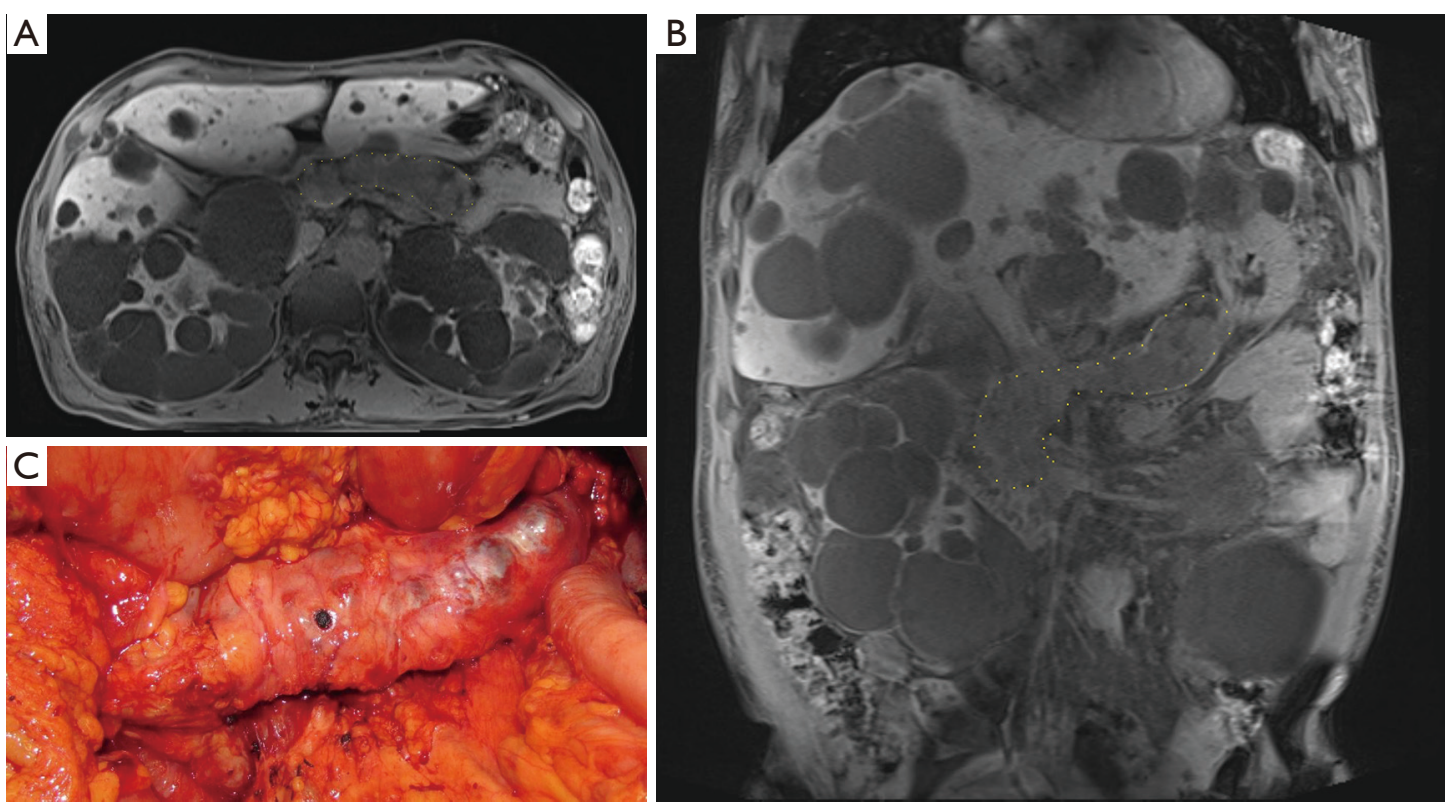

Figure 1 MRI finding indicate the mass in whole pancreas (A,B). Gross picture of ITPN filled with mass lesion in whole pancreas (C). MRI, magnetic resonance imaging; ITPN, intraductal tubulopapillary neoplasm. 


\section{Acknowledgments}

Funding: None.

\section{Footnote}

Conflicts of Interest: The author has completed the ICMJE uniform disclosure form (available at http://dx.doi. org/10.21037/hbsn.2020.02.05). The author has no conflicts of interest to declare.

Ethical Statement: The author is accountable for all aspects of the work in ensuring that questions related to the accuracy or integrity of any part of the work are appropriately investigated and resolved. Written informed consent was obtained from the patient for publication of this manuscript and any accompanying images.

Open Access Statement: This is an Open Access article distributed in accordance with the Creative Commons Attribution-NonCommercial-NoDerivs 4.0 International License (CC BY-NC-ND 4.0), which permits the noncommercial replication and distribution of the article with the strict proviso that no changes or edits are made and the original work is properly cited (including links to both the formal publication through the relevant DOI and the license). See: https://creativecommons.org/licenses/by-nc-nd/4.0/.

Cite this article as: Paik KY. Intraductal tubulopapillary neoplasm (ITPN) of pancreas with polycystic kidney and liver disease. HepatoBiliary Surg Nutr 2020;9(4):562-563. doi: 10.21037/hbsn.2020.02.05 